\title{
The museum as a dating venue: Couples in the Madhya Pradesh Tribal Museum in Bhopal, India
}

\author{
Ina Ross*
}

\begin{abstract}
Using the example of the Madhya Pradesh tribal Museum in Bhopal, India, the following article deals with a romantic user interest in museums: as a meeting place for unmarried couples; in short, as a venue for dates. ${ }^{1}$ The article contextualizes this phenomenon by taking into account the relationship of the museum as an institution with its Indian visitors from a historical perspective, and by outlining the social context within which public intimacy is situated in present-day India. It interprets the utilization of museums by dating couples as a process of appropriation which acquires special significance in view of the frequently cited inadequate entrenchment of museums in India.
\end{abstract}

As requirements of the couples from the museum as a dating venue, the essay identifies the ambience and the discreet behaviour of personnel, a lack of surveillance by family or neighbours, the positive (since it contributes to education - including moral education) social image of the museum as an institution and, finally, economic reasons. However, what emerges as the central motive, as a prerequisite for the safety and sense of comfort of the couples, is the disciplining effect of the museum as an institution on other visitors.

The discussion of the museum as a venue for dating is part of a research project about the user interests of visitors to the Madhya Pradesh Tribal Museum in Bhopal, India. In the study, about eight different categories of utilization were worked out including the museum as a picnic spot and hang-out place, as arts and leisure centre, as a space of collective nostalgia and personal memories and as a backdrop for photos and selfies.

Key words: Indian museum, dating, museum as a dating venue, museums visitor India, audience research, arts management

\section{Madhya Pradesh Tribal Museum in Bhopal - An Introduction \\ The state of Madhya Pradesh (MP) in Central India is known for its rich and diverse Adivasi culture. The Tribal Museum was inaugurated in the capital, Bhopal, in 2013. While the museum aims to attract an urban public, it also caters to the Adivasi communities themselves. Situated in the midst of a museum complex, the building and its spacious grounds are within walking distance of two other institutions, the State Museum of MP and the National Museum of Mankind. ${ }^{2}$ The exhibits in the Tribal Museum portray the everyday life and spiritual world of Adivasi communities as well as their art. Relying not only on original works and pieces, the museum also has larger-than-life reconstructions and replicas that lend themselves well to its large rooms and spacious grounds. The focus of the display is not on individual exhibits but on installations and tableaux made up of a variety of objects (wall paintings, sculptures or articles of daily use). The Museum receives up to 71,000 visitors $(66,000$ Indian nationals $-5,000$ foreign nationals) per year. ${ }^{3}$ Compared to other Indian museums, which are often plagued by a lack of visitors and meagre public perception, it attracts vigorous public interest, and draws visitors from a wide social, demographic, and religious spectrum of influences and backgrounds.}


The gallery floor of the museum is frequented by visitors and monitored by the personnel. As soon as one leaves the rooms on this floor and reaches the lower level of the museum, one notices the young couples withdrawn into quiet corners, sitting on ledges or occupying a sheltered spot outside in the jungle-like garden. Some have brought along tiffin boxes (the metal lunch containers, often 'multi-storeyed', which are common in India) and water bottles, and are eating together. The vast majority of these couples are young, in their twenties. There are some older couples too, but they are clearly in the minority.

Often the couples sit with their backs to the interior, facing the garden outside. Their posture clearly proclaims: 'Please do not disturb.' In this way they create private two-person spaces which have an exclusive, almost conspiratorial character in what is otherwise an open and public building. The couples sit close together but there is no physical contact whatsoever such as hugging or kissing. Their body language does not show any signs of erotic tension or sexual desire.

In fact, the interviewees or the other couples encountered in the museum are not even seen holding hands. On the other hand, same-sex friends often hold hands and embrace while sitting together. It is not uncommon to come across men, for example, holding hands while walking together or, sitting together with one man's arm draped around the shoulder of the other in a friendly gesture. Not so in the case of couples. Intimacies in public between members of different genders can be seen as a violation of public order and have legal repercussions. ${ }^{4}$ Above all, they are socially tabooed, and dating in public space is not without risk for unmarried couples. Even highly controlled spaces which one would expect to be perceived as morally inoffensive, such as the mosque for Muslim women, are nonetheless rated as 'moral danger zones' by their families. Sadaf (20), a Muslim girl visiting the museum for the first time with a male classmate, says in response to a question about mosque visits: 'Actually we don't go to the mosque. It's mainly the boys, the men who go there. (...) Because there we will encounter all the men and that is something which is not allowed. ${ }^{.5}$ Even though religious rules allow the presence of women in mosques, it is seen socially as undesirable, and many women pray at home.

\section{'Deficient' museum visitors in India - a problematic narrative}

This article will represent the utilization of the museum as a dating venue and place it in the context of reflections on Indian museum visitors. As illustrated by the positions referred to in the following paragraphs, museum visitors in India tend to be perceived as somehow deficient ever since the colonial era; often they seem not to make the 'right' use of the institution. In fact, Indian society as a whole does not really seem to be able to make proper use of the institution of the museum. I will argue, however, that the example of the dating couples in the MP Tribal Museum shows that the visitors are able to form an intensive and specific relationship to the museum, and know how to harness it for their needs. They appropriate the institution - but not in a form which corresponds to the expectations shaped by the western (and largely accepted by the indigenous Indian cultural elite, too) museum tradition.

The notion that the museum represents a foreign object in India, and that it is, thus, not really embraced by the public is widespread. It is e.g. articulated by the art historian and founding director of the National Handicrafts and Handlooms Museum (Crafts Museum) in Delhi, Jyotindra Jain: 'Considering the fact that the conventional museum model from another cultural milieu has largely failed in India in terms of wider public engagement, it may be time for us to rethink the model...' (Jain 2012). According to him, the Indian public has not developed any attachment to the institution of the museum. In his opinion, it is 'a potted plant, grown to become a cultural artifact for its own sake without taking roots in the diverse cultural soils of the country' (ibid.). When Jain talks about the museum originating in 'another cultural milieu' and representing a 'potted plant' in India, he is obviously thinking of the fact that museums were introduced to India in the nineteenth century by the British colonial rulers.

Occasionally some authors try to embed the museum retrospectively in the pre-colonial history of India, such as the museologist N.R. Banerjee with regard to labelled sculpture exhibitions in temples or private collections: 'They did serve the purpose of museums though they were not surely named nor mentioned as museums of any kind' (Banerjee 1990: 14). 
However, most of the works about Indian museums interpret it (with reference to collection and exhibition, as well as in the sense of the institutional concept) as a colonial import and colonial legacy, and deal with the effects of this past on the present-day institution (Prakash 1992; Guha-Thakurta 2004, 2015; Jain 2012; Appadurai and Breckenridge 2015; Roychowdhury 2015; Mulgund 2015; Singh 2009; Mathur and Singh 2015).

One of the reasons for the lacking entrenchment of the museum in India as diagnosed by Jain is the distrust which the colonial museum makers showed for the Indian public. The comprehension as well as the behaviour of the people seemed deficient to them. Art historians Saloni Mathur and Kavita Singh sum up this perspective: 'Indian museums-goers were seen by colonial officials as an uneducable or 'uncivilisable' public' (Mathur and Singh 2015: 204). Historian Tapati Guha-Thakurta notes that the visitors were perceived as an impediment to the development of the institution and for the evolution of its scientific and educational potential (Guha-Thakurta 2004: 79-80). This tendency to declare the Indian public as a problem, which has been discerned by Guha-Thakurta, went even beyond the characterization of the visitors as 'strangers' which Doering notes for European museums in the eighteenth and early nineteenth century where the public was expected to be thankful that 'it has been granted a special privilege' (by being admitted as visitors (Doering 1999: 1).

The suspicion towards the indigenous museum public did not disappear even after the end of colonial rule. Independent India experienced a wave of museum establishments, among them the National Museum of Natural History and the National Gallery of Modern Art in Delhi. A remark by the first Prime Minister of India, Jawaharlal Nehru, at the inauguration of the National Museum in Delhi in December 1960 shows just how the idea of the unenlightened museum visitor continued to be entertained even under the new circumstances:

The museums are not just places to see things or ajayabghars [House of Wonders], as they used to be called. They all should be essential part of the educational system and cultural activities of the country. What is more, they are places for public education (Banerjee 1990: 120-121).

Perceiving the museum as a 'House of Wonders' is the misunderstanding which Nehru ascribed to the bulk of his compatriots. To counter this, a new conception of the museum as a serious cultural and educational establishment had to be asserted.

The sceptical image which the institution and its representatives have of the users can be clearly seen even today, for example in the National Museum with its high density of prohibitive signs ('No spitting', 'No touching', 'No praying', 'No smoking') (Ross 2015: 18). The visitors appear as disorderly by tendency, and not up to the requirements of civilized behaviour demanded by the place; the museum presents itself with an authoritarian gesture, as an institution which wants to control and educate its users. There are primarily two patterns of behaviour which defy the norms of the museum, and are thus combatted by the museum management. The first of these is the tendency of Indian visitors to touch objects (Elliott 2006; Jeychandran 2015). The other is the non-recognition of the secular character of the museum, such as when Indian visitors perform religious rituals in front of the exhibited objects (Ross 2015; Mukherjee 2015). Mathur and Singh characterize this unorthodox public behaviour summarily as the 'notorious unwillingness on the part of India's subaltern masses to follow the museum's cultural script' (Mathur and Singh 2015: 9).

These difficulties which are inherent in the Indian museum's dealings with its public find an echo in the fact that there is hardly any empirical research on the visitors. The only study so far to deal qualitatively with a specific segment of visitors in an Indian museum is the investigation carried out in 1985 by Naqvy, Venugopal, Falk and Dierking in the National Museum which focused on families and the length of time they spent at exhibits (Naqvy and Venugopal; Falk and Dierking, 1991).6,7

\section{Dating and its spatial and social prerequisites in India}

In order to assess the interest of dating couples in the MP Tribal Museum and their utilization praxis, it is necessary to take a brief look at the social conditions which govern the public expression of intimacy and partnership in India. The country is going through a phase of 
modernization and upheaval, and this also extends to the sphere of love and sexuality. Brosius notes that '(o)ne of the most passionately and violently fought battles (...) is that of intimate love relationships, unravelling modernity's ambivalence in terms of its qualities and the whereabouts of empowerment and restriction.' (Brosius 2011: 28) In her manifesto Trivedi goes so far as to claim that a 'love revolution' (Trivedi, 2014: 380) led by the post-libralization generation is presently underway in Indian society. Many authors establish a close connection between economic conditions, consumer behaviour and societal attitudes to explain the emergence of new concepts of individuality, choice and love while hinting at potential friction with conservative social forces (Dwyer 2000; Mazzarella 2001 and 2014, Srivastava 2004 and 2007, Lukose 2005 and 2009, Orsini 2006; Brosius 2011; Donner et al 2016). Most authors emphasize that this does not entail a simple and straightforward replacement of the 'old' (arranged marriage, priority for the collective over the individual, joint family system, all manners of restrictions) with the 'new' (individuality, partnership without marriage, comprehensive liberalization), as the term 'revolution' would suggest. Instead, the present times are characterized by hybrid behaviour patterns and lifestyles, a juxtaposition of the traditional and the modern and a constant process of negotiating between individual needs and societal expectations.

The fact that couples, as observed on the Bhopal museum grounds, look for public places for what are actually private and intimate encounters can only be understood against the backdrop of the domestic situation of most Indians. Bijapurkar observes:

If you are modest income to poor, and live in a big city, you can have a cell phone, very nice clothes (...), earn reasonably well doing housework in upper-class localities but live with several other people in a tiny space with a shared toilet... (Bijapurkar 2013: 140).

Owing to the often tight accommodation situation, private space is a rare commodity for all members of an Indian household regardless of their age and relationship status. There is constant monitoring by family members, especially in joint families. ${ }^{8}$ The ubiquitous 'aunties' are particularly notorious for their controlling zeal - a classical theme of jokes in India. Consequently, couples are forced to seek opportunities for significant, autonomous togetherness in the public sphere, thereby virtually converting public places into spaces for the private.

A popular meeting place for young couples in every Indian city are parks and green areas. However, as determined by Phadke, Khan und Ranade in their study on Mumbai's public spaces, there is an uneasy relationship between the very presence of couples and the normative layout of these places: 'Parks as open public spaces are also used to impose a specific "moral vision" of order in the city (...) this morality is peculiarly directed at public displays of romantic affection, and sometimes, even the mere presence of couples' (Phadke, Khan and Ranade 2011: 90). ${ }^{9}$ The pressure is exerted not only by the police or supervisory staff, but also by other citizens and citizen groups who want to see their moral values enforced in public places: 'Citizens' groups would like parks to comply with notions of middle class aesthetics and morality' (ibid).

The new consumer culture in India has opened up additional spaces for couples to frequent, like coffee shops, shopping malls or multiplex-cinemas. They are characterized by an easing of the familial control experienced at home. In contrast to parks or other public spaces, there is no danger of harassment by moral guardians, 'creeps' or rowdy elements. However, some of the new commercial places are difficult to access for couples from the lower middle class since they will charge too much money. Besides, the amount of time they can spend there is restricted by personnel (for example in coffee shops, cinemas, ice cream parlours). Other places require a certain class status (for example, shopping malls).

For the museum, by contrast, barriers to access are few. The entrance fee for Indian nationals is ten or sometimes 20 rupees. In the Tribal Museum in Bhopal, entry is free if visitors only use the canteen. Unlike with shopping malls, there is no social discrimination in museums: the security staff do not look askance at anybody or deny admission to them because they do not look like they have sufficient spending capacity. As the survey of the visitors in Bhopal shows, there is a wide range as far as social status is concerned, which is not found among clients in shopping malls or coffee shops.

At the same time it should be noted that as an established cultural institution which is 
regarded with a certain respect, the museum has a more pronounced disciplining effect on its users than other public or commercial places. From the point of view of the couples, this means other users who could potentially bother and harass them will be more restricted. This effect of regulating and self-regulating visitor behaviour in the museum in the West has been extensively described and analysed by Hooper-Greenhill in 'The Museum in the Disciplinary Society', Bennett in The Birth of the Museum with recourse to Foucault, and by Duncan in Civilizing Rituals among others. (Hooper-Greenhill 1989, Bennett 1995, Duncan 1995). In India, there is an added 'respectability effect' - which counteracts the permanent moral suspicion directed towards dating couples. Since the museum is held in high esteem as a place of public instruction (also in a moral sense), a rendezvous within its limits arouses less suspicion of immorality as compared to, for instance, a meeting in a park.

That the Tribal Museum in Bhopal lends itself particularly well to dating is expressly confirmed by the students Zaina (20) and Kriti (20), who are here for the first time. ${ }^{10}$ When asked if they could also imagine coming to the museum for a rendezvous, Zaina answers: 'We feel that this is the perfect place for it. We talked about it already when we saw a couple here. Both of us thought immediately that this is the perfect venue for a date.' Kriti adds: 'Because this place is different, somehow a unique venue for a date, a good place for couples of all ages.' The fact that young people like Kriti and Zaina are constantly in search of places with these qualities, hints at the scarcity of this resource. The two women are scouting even though for the time being their visit to the museum has nothing to do with dating intentions.

Yet, it is the subject of their conversation, even in the absence of any discernible reason. Kriti's postscript is also interesting: '... a good place for couples of all ages.' Indeed, one sees older couples in the museum too, even if they are clearly in the minority. I noticed two, but they were not willing to be interviewed. Unlike coffee shops, for instance, which are clearly perceived as spaces for the youth and younger professionals in cities, the museum is evidently perceived as less generation-specific and milieu-specific.

\section{About the method}

The present article is part of a more extensive study on the visitors in the Madhya Pradesh (MP) Tribal Museum in Bhopal and the various utilizations of the institution. The selection of the museum for the purposes of this research is based on the author's own preliminary empirical observations in various Indian museums (Ross 2015). As mentioned already, empirical studies or theoretical explanatory approaches to the museum visitors, their requirements, and appropriation strategies are rare in India. Against this background, theoretical assumptions which would have to be verified in the research process cannot be the starting point for the study of the Tribal Museum in Bhopal. Therefore, an approach partially based on the iterative heuristics of the Grounded Theory (Strauss 1994) was chosen. The theoretical distinctions which inform the analysis of the empirical material were gradually derived in the course of the research process. Of primary importance was the development of typological distinctions which would allow the author to distinctly work out the different ways in which the public utilizes the conditions in the museum, in order to render the logics of utilization and appropriation visible, and to explain them conceptually. At the same time, these object-oriented theoretical distinctions are being subjected to a step-by-step review in the ongoing research process.

For the study, a total of 80 qualitative interviews were conducted in Hindi and English with visitors to the museum over a period of two years (2015-2017). The interviews had a length of approximately 10-30 minutes. The interview phases were spread over the year (in consultation with the museum management) in such a way that various visitor segments could be covered. In addition to the interviews, on-site observations were also carried out. The interpretation of the statements made in interviews is also based on written protocols of the observation of visitors with this motivation. The observation protocols as well as the interview records were evaluated on the basis of qualitative content analysis (Mayring 2015). In addition, individual passages in the interviews were interpreted with hermeneutic methods oriented to sequence analysis (Reichertz 2017).

In the study, eight different types of utilization were worked out including the museum as a venue for dating, as a picnic spot and hang-out place, as a space of collective nostalgia 
and personal memories and as a backdrop for photos and selfies. The typologically different ways of utilization were then interpreted at an abstract level with a systematic recourse to theoretical knowledge about the social context (in the case of the dating couples, this includes the spatial and social conditions under which intimacy can be experienced publicly in India). Besides visitor interviews, further sources of material for the study are interviews with politicians as well as with artistic and administrative personnel, the visitor book analysis (Ross 2017) and analysis of written documents such as museum concept papers and museums reports.

\section{The interviewed couples in the museum}

Compared to other visitor groups, it was more difficult to find interviewees among the dating couples who were willing to speak about their specific user interest and their expectations from the museum. Also, this group is reluctant to share personal details; this is especially true of the women. And yet, unlike the couples on the grounds or in the corners of the museum who really did not want to be approached, the couples in the canteen were often willing to talk. Five unmarried couples were interviewed on the topic of 'The museum as dating venue'.11 Two of the interviews were conducted in Hindi, and three in English. The museum personnel partly helped in choosing the interviewees since some of them are known as frequently visiting couples. All the interviewed couples were between 20 and 30 years old (the oldest person interviewed in the group was 26 years old). All the interviewees who furnished their personal details were students at one of the colleges in Bhopal. The uniformly high educational level of this group constitutes an exception compared to the other user groups covered in this study. ${ }^{12}$ The names of all the interviewees have been changed to preserve their anonymity..

Syed (22) and his girlfriend are a Muslim couple..$^{13} \mathrm{He}$ is studying at an Industrial Training Institute (ITI) in Bhopal. His girlfriend did not want to provide her name or any other personal details. Syed claims that this is his second or third time in this museum. This is contradicted by the statement of the museum personnel who are familiar with the two of them as a regular dating couple.

Siddharth (26) and Anuradha (21) are regular visitors to the canteen. ${ }^{14}$ They meet each afternoon besides Mondays (the museum is closed on Mondays) after 1 $\mathrm{pm}$, i.e. after the end of college classes, in the canteen. Siddharth is from Nagpur and is enrolled in a Masters programme in Chemical Engineering. ${ }^{15}$ Anuradha is from Bhopal and is aiming for a Masters in Business Administration (MBA).

Amit (25) and his girlfriend Suchika (23) are both pursuing a B.Com (Bachelor of Commerce) in Bhopal. ${ }^{16}$ Amit also works as a teacher and manager of a school. He used to live in Delhi but since his civil servant parents were transferred to Madhya Pradesh (MP) he now lives in Bhopal. He is the only one to indicate his caste (Jat).

Snehil (24) and his girlfriend Deepika (23) meet as per their own statement often in the museum, i.e. at least once or twice a month. ${ }^{17}$ They are both students in Bhopal. However, they did not want to provide any further personal details.

Aditi (22) and Jitu (24) are both students in Bhopal. Jitu is studying law, Aditi is pursuing an MBA..$^{18}$ Both stated that they had come to the museum to 'hang out' and 'chill'. They were here for the first time, on the recommendation of friends.

\section{'Boyfriend' and 'girlfriend' - tricky labels}

Right at the beginning of the interview, Siddharth declares loud and clear into the microphone: 'Hi, my name is Siddharth and I am here with my girlfriend.' Anuradha, who hardly speaks any English but still understands the word 'girlfriend', is visibly embarrassed. That the designation 'girlfriend' or 'boyfriend' connotes something which is morally questionable is also confirmed by 
the behaviour of Syed and his girlfriend. Even though both of them are known to the museum personnel as a couple, and he also expresses his views on the qualities of the museum as a dating venue later in the interview, he answers in the negative when faced with a direct question about whether they are 'boyfriend' and 'girlfriend': 'No, we are friends.' And reiterates for added clarity: 'Only friends.' The question is fraught with different degrees of volatility for men and women. Syed's insistence on the difference between 'friends' and 'boyfriend/girlfriend' could be a protective gesture for his female companion: he is Muslim, she is probably, too, and the rules of propriety for young women in the Muslim community tend to be even more restrictive than among Hindus. In the interview with Aditi (22) and Jitu (24), the latter answers the question about whether the girl with him is his girlfriend in the affirmative with a sheepish laugh. Then his partner intervenes forcefully in the conversation: 'Girlfriend? Who said I was the girlfriend?' When asked what is so bad about the word 'girlfriend', Jitu answers cautiously in a hesitant voice: 'Actually, because this is India....'

The social role of 'girlfriend' implies premarital sexual intimacy which does not correspond to social norms. There are gender-specific differences not only in the statements but also in the behaviour of the interviewees. Thus, all the men readily agreed to be photographed with their girlfriends after the conversation. The women, on the other hand, were more hesitant. Suchika insisted on not being photographed with her boyfriend Amit. However, she had no objection to being photographed alone. Syed's girlfriend did not allow a photo, nor did she reveal her name (not even her first name).

\section{Museum canteen or coffee shop?}

No entry ticket needs to be bought to use the canteen, and tea, coffee or small snacks are priced in the range of 20-60 Rupees (27-80 cents). Hence, they are clearly more affordable than the dishes or hot drinks in coffee shop chains like Cafè Coffee Day (CCD), Barista or Costa Coffee which are also frequented by young people, but charge 170 Rupees (approximately 2.30 Euros) on average for a milk coffee or tea. Besides, the density of coffee shops in smaller cities like Bhopal is lower than in Indian metropoles like Delhi and Mumbai, or in the decidedly modern city of Bangalore. However, it is primarily because of the prices that visiting them remains a privilege of the upper middle class and their children. ${ }^{19}$

Siddharth describes the disadvantages of a coffee shop in comparison to the museum canteen in the following words: 'In a coffee shop you feel boring and it is expensive.' When Jitu and Aditi are asked why they do not meet in a coffee shop instead, Aditi says:

Actually the main reason is in the interior. It is so impressive [...] Just because of the interior and the ambience we are here. A coffee shop does not have this much. [...] So that is the reason why we came here.

The disadvantage of the coffee shop according to Amit is that such places are too popular in his social peer group and he runs the risk of being disturbed there by acquaintances or friends. 'When I want to talk' (he had earlier given this as the main reason behind coming to the museum with his girlfriend):

I don't have much time for [other] people. I am also not that kind of a public person. It is a bit more confidential here. [...] I have so much work. I have not that much time for hanging out.

Although, as a part of the youth culture, coffee shops offer a largely 'safe' space without surveillance by older family members vested with authority, there is yet another form of social control exercised within their walls: the couples run the risk of being seen by acquaintances, fellow students or colleagues, and being harassed by their comments and demands for attention. Amit emphasises specifically that he has no time to 'hang out'. Seen from his perspective, hanging out seems to be the normal form which the use of public spaces by male youths like him takes. He, on the other hand, deliberately deviates from this norm by opting for the counter model of visiting the museum. Due to the tight living conditions in the household sphere described earlier, hanging out in the public sphere often represents the only chance for young 
men to establish a certain semi-privacy within a group. In addition, Amit's remark again draws attention to the fact that this option is generally not available to women, because, as Phadke, Khan and Ranade point out: 'Women [irrespective of their class] don't loiter' (Phadke, Khan and Ranade 2011, vii).

\section{'Relationship use' versus 'cultural and educational use'?}

All the interviews in this group took place in the canteen. For Aditi and Jitu, the canteen was right away the most attractive part of the entire museum: '[...] we directly came and sat here. We haven't gone through any of the places yet. Actually we saw the board here. The arrow for the canteen and we came directly here. This signboard is right at the entrance.' This couple had come to the museum for the first time and had not seen the exhibition yet. They were tipped off about visiting the museum by their friends. Hence, it can be assumed that the friends' recommendation related to the qualities of the museum as a dating venue, and not as an exemplary space of cultural experience. Snehil and Deepika also professed: 'We have visited the museum before but we don't know deeply about it.' At the time of the interview, they were only using the canteen. The museum was patronized by them solely as a dating venue, and the couple seemed to have little interest in its cultural offerings.

When asked whether he and his girlfriend see the exhibition or come directly to the canteen, Siddharth answered:

Yes, we have seen it [the museum] many times. Nowadays, we are only coming for the canteen. [...] Many of my friends who also meet their girlfriends here come in the evening. In the evening the museum is very beautiful.

He still remembers his first visit to the Tribal Museum: 'So he [a friend] told me: You go and see. [...] when I came with him I was really surprised. It is really good.' Besides their regular visits to the canteen, the couple occasionally attends the programmes in the evenings, especially the dance programmes. The fact that the museum is especially attractive to couples in the evening is connected on the one hand to the romantic and scenic atmosphere in the evening. On the other hand, not all parts of the building are brightly lit in the evening, and this undoubtedly plays a role, too. Even the grounds only have soft lighting which makes them less visible than in the daytime. During the evening programmes, the visitors gather outside at the amphitheatre, and the rest of the complex, including the canteen, is largely deserted. At such times even the attention of the supervisory staff is mostly absorbed by the performances, and the employees abandon their posts in search of a good vantage point. Dating and a romantic ambience conducive to it were paramount for this couple. Nevertheless the two of them were also amenable to and interested in the museum's cultural offerings.

Syed recounted: 'First time I came to see the art and how it is [...] I got to know about the museum. First I came with my family. And after that we [his girlfriend and he] started coming here slowly.' Unlike Snehil and Deepika, for example, who admitted that they do not know much about the exhibition, Syed talked about the exhibits:

Art is here. People [Adivasis] are so artistic. They have made so beautiful art with a rope. I got to see paintings that are done by villagers in the village. People who live in a city don't get to see these types of paintings.

He expressly confirmed visiting the galleries time and again besides his dating visits to the canteen: 'If anybody comes to Bhopal then I bring them and show the museum.' Syed's example shows the fact that interest in the museum as a dating venue can overlap with an interest in the exhibition. As in the case of Siddharth and Anuradha who go to the museum for their rendezvous as well as for the evening programmes, Syed's usage of the museum also alternates between 'relationship use and 'cultural use. The various offerings of the museum are taken advantage of in a given situation as per the requirement and social context (visit with family, friends or partner). ${ }^{20}$ 


\section{Why couples feel comfortable here - the well-ordered freedom in the museum}

When asked why they prefer to come to the museum, the most common keyword in the couples' response is 'feeling comfortable'. The aspects which were enumerated as crucial for this feeling of comfort varied from one couple to the other, but were similar in essence. Siddharth stated: 'We feel comfortable because of the garden also and this canteen. We bring our own food or sometimes we take it from the canteen. The open space we like both.' The term 'open' can be interpreted in two ways here. On the one hand, it can mean 'airy' in the sense of the canteen being open to nature on all sides. Siddharth, however, probably used the word in the sense of 'free' and 'informal' with reference to the easing of the oppressive, constricting social norms.

For Syed, feeling comfortable consisted primarily in the enjoyment of a private sphere: 'We can spend peaceful moments here in the museum. It is silent and we are not disturbed.' The term 'calm' can again be interpreted in two ways here. On the one hand, it is the opposite of the ubiquitous noisy, hectic Indian city. On the other hand (and this is what the second sentence indicates), it denotes the opposite of the stress induced by the risk of being seen or disturbed, including the possible consequences which being caught in public places can otherwise lead to. When asked whether not being disturbed also means not being seen by family members, Syed answered: 'This is also a reason for sitting here.' Would other museums be equally suitable? Answer: 'This is better because it is associated with nature.' Besides its idyllic character, nature also has a protective, concealing quality.

Amit expressed the most clearly how important the discretion offered by the museum is. Also interesting is the fact that in these parts of the interview his otherwise loud and confident voice became distinctly lower (occasionally hardly audible in the audio recording) and his tone confidential. In response to the question whether he likes this place and whether he would come back here with his girlfriend, he initially stated briefly: 'Yes, definitely. It is a calm, peaceful, decent place. People are decent.' When further asked what 'decent' meant in this context, he said:

Decent in my perspective is about the crowd. The behaviour. The people, you know... [his voice becomes low here] Nobody gives a shit what we are doing here. But the normal crowd people as well as personnel, frankly speaking they are staring. It's an Indian mental thing. [...] When people are roaming around somewhere and find this kind of thing [couples meeting up], you know, then people just start staring and all this shit. Sorry, but.... [he laughs sheepishly].

Amit is referring here to parks and the waterfront in Bhopal mentioned earlier. The special character of the museum as opposed to other public or semi-public spaces becomes clear in his testimony. Of primary importance to the couples is that they get freedom for their own conduct in the museum. Unlike in other public places, this individual freedom is not curtailed in the museum by the unwanted attention of, or expression of disapproval by, other visitors. Why do the couples remain undisturbed in the museum? It is not, as in a coffee shop, because of a restrictive social composition of the visitorship, since visitors from all classes are found in the Tribal Museum. Instead, the museum seems to exercise a collective disciplining effect on its visitors because of other reasons. Bennett has already demonstrated this educative-disciplinary function for the historical beginnings of the public museum: '...the museum [provides] new codes of public behaviour which drove a wedge between the respectable and the rowdy.' (Bennett 1995, 102) The Tribal Museum in Bhopal provides an example of this mechanism. ${ }^{21}$ It offers the couples a space of well-ordered freedom within which 'liberation' and 'disciplining' paradoxically go hand in hand. The couples enjoy individual freedom because the collective around them is disciplined by the institution. Museum visitors do not stare and do 'all this shit', as Amit puts it. At the same time, the behaviour of the couples also keeps within a regulated framework, and there are no real transgressions against propriety, as avouched by Amit:

And look. What we are exactly doing here? We just make conversation. And that is all what we are doing. We need hours for our conversation. [...] It is just about conversation only. I need a good and decent place, where I can talk for hours. That's all. 
The embarrassment in this declaration and the laughter which accompanies it once again draws attention to the delicate nature of the topics discussed. Even when talking to me, a western interviewer who does not represent Indian social norms, it seems necessary to emphasize that these norms are not violated in any way.

Nature is important for Snehil and Deepika, too. Equally important is, however, the behaviour of the staff. When asked about the qualities of the museum, they answered:

The place is good. This place is empty and it's comfortable only for sitting here because of the loneliness, less people, less gathering. It is surrounded by nature, the surrounding is good, the nature is good and it's calm here. It is comfortable because the people [staff] here they won't let us feel uncomfortable here.

When asked whether this implies not being monitored, Snehil affirmed: 'Yeah, just that.' If a couple is made to feel 'unwelcome' by society, being 'lonely' becomes attractive. For Snehil being 'lonely' here primarily means 'not being monitored' or 'not being disturbed'. It does not really refer to the museum being deserted. During working hours there are constantly other people present in the museum, as well as in the canteen. However, the couples do not feel subjected to surveillance here, and this opens up a space wherein they can interact as a pair. That the Tribal Museum is not the only suitable venue for a rendezvous is revealed by Amit referring to the example of the neighbouring Museum of Man:

It is very popular out here. Even though I would say[...] there is a different museum in the back. [His voice becomes lower and more confidential again.] I have been there twice. There is so much space. I found much more couples there. Many couples go there.

His confidential tone of voice at this point in the interview seems to suggest that he is not talking about intimate conversations among couples any more, but rather about sexual encounters. With this, he hints at a space where the usual disciplining effect of the museum is ineffective. The reason for this, according to him, is to be found in the uncontrollable, extensive grounds attached to the Museum of Man. In comparison, the Tribal Museum seems like a place where freedom and moral respectability coexist.

\section{What the couples do not like}

When asked what should be changed in the museum, Siddharth answers: 'I think the museum should have romantic songs in the background. That attracts the people.' Anuradha adds: 'And the tables should be cleaned.' Like the ice cream parlour owner in Kerala who takes young couples and their wishes seriously as potential clients, Siddharth wants the museum, too, to see itself consciously and expressly also as a dating venue and to adapt itself to this use and the corresponding 'clientele'. ${ }^{22}$ As far as he is concerned, there does not seem to be a predefined concept of a museum which would be challenged by its utilization as a venue for dating. He uses the museum and all its various offerings concurrently, and wants to see the different uses supported on an equal footing.

Snehil and Deepika had no complaints and did not want anything changed. Syed was equally satisfied. In contrast, Amit initially said in response to the question about possible improvements: 'Should be some changes. But since I don't want to be so demanding [...]' When requested to express himself, he criticized the atmosphere in the canteen:

I cleaned my table myself and all this. Nobody bothers. The people roam here and they don't have manners, or behaviour. [...] And see, they are also littering here...

Amit wants a beautiful, clean setting without garbage, a notorious problem in Indian public spaces, for his visit. In addition, he wishes for civilized behaviour from the others present, even if they are not visitors to the museum. 


\section{What does 'museum' mean for the couples?}

The couples interviewed either encountered the phenomenon of the museum for the first time in the Tribal Museum, or they had visited the neighbouring Museum of Man prior to this. According to Amit's statement, the dating aspect seems to have played a decisive role in his visit to the Museum of Man, too. For Snehil and Deepika the Tribal Museum was their first contact ever with this kind of an institution. When asked what a museum is for him and his girlfriend, Snehil answered: 'We do not know much about museums. We would say: what we see here around us.' Siddharth initially provided an unusual definition which was oriented to his own emotional reaction: 'Actually I think... museum is a chemical reaction. A chemical reaction in our heart.' When he noticed my surprise, he followed it up with a more prosaic definition: 'A museum is a place where we can see old things and live that old time.' It may be assumed that Siddharth's first, spontaneous definition was prompted by his own approach to the museum as a dating venue. He sees it primarily as something which correlates to his feelings. It is only the surprised reaction of the interviewer that reminded him of the fact that this place can also be seen in a different way, that it is, in fact, conventionally seen differently - and then he came up with a more traditional definition.

Amit, who had earlier contrasted the unobtrusive behaviour of museum visitors with the intrusiveness of passers-by elsewhere in the city, defined a museum in the following way:

...It is a place to calm down. Actually the thing is.... The whole day we have work, this is what we do, we talk ... This kind of place makes us calm and we can observe things ... We try to find out actually. Like.... Wow, how have they done these things? Although the things are not alive.... This kind of vibes.... They generate life. ... There is so much art here in these objects... artistic aura I should say. This artistic aura is there and this actually leads the visitor towards a specific kind of thinking. Make them calm and let them think about it...Art will get you...

Amit sees the museum as a place which indirectly and spontaneously initiates an inner process of experience and education, ensuing from the aura or charisma of the objects, and leading the visitor to greater contemplation. Going by Amit's other statements, it may be assumed that it also leads the visitor to greater tolerance, such as towards couples. Furthermore, in his view, state authority should be harnessed to reinforce this process of education more strongly in the case of the museum staff or the workers employed in the museum.

\section{Conclusion}

By using the museum as a dating venue, the visitors presented in this study adopt it as their own; in other words, they appropriate it. The concept of appropriation in the sense of the adaptation of the 'imported' museum idea and institution to local requirements is occasionally used in the discussion about Indian museums. However, this is done so less in the sense of appropriation by the visitors, and more as seen from the perspective of the state and the nation, as a cultural policy of 'appropriation of the museum to nationalist ends' (Mathur, Singh 2015: 6 ). In this regard, the focus is on the contents of the exhibition and the manner of presentation in which the self-image of a sovereign, diverse and, at the same time, integrated nation is supposed to be expressed. There is, as determined by Mathur and Singh, "through systematic appropriations and erasures of various regional and temporal phenomena, a civilisational history (...) produced for India' (ibid). The political vision of 'unity in diversity', the state doctrine of independent India, is to be visualized in and through the museum.

The interviews presented and interpreted in this article show a different form of appropriation: not 'top down', but 'bottom up' - an appropriation which takes place in the concrete practices of the visitors. It navigates their needs, the social limitations which they are subjected to, and the leeway which is available to them, or which they are able to create for themselves. They make use of the institution in their own way, without much deference to the normative 'cultural script' (Mathur and Singh 2015) of proper museum utilization which has been upheld since the colonial epoch and all the way up to the present. In addition, they are able to forge a relationship to the museum, as attested by the quite emotional statements of 
some of the interviewees. The museum itself facilitates this process by not imposing sanctions on the couples or reprimanding them, instead offering them a space of 'well-ordered freedom', in which, owing to the disciplining of the other visitors, they are able to comport themselves largely unconstrained as a pair. This is the reason why, as pointed out, the security the museum provides and the decent, civilized behaviour it expects from all visitors are so important for the couples. Although they are confident enough to make use of the museum the way they see fit, at the same time they deeply respect the institution and its culture.

As has become apparent, the dividing line between their 'unorthodox' utilization (from the point of view of the institutional tradition) and a 'regular' utilization of the museum for cultural and educational purposes is neither sharp nor impermeable. Instead, it permits crossovers. Although the main user interest (and occasionally the only one) of the interviewed couples pertained to the museum as a dating venue, 'relationship use' and 'cultural and educational use' did overlap in this group. They expect the ambience to be rich in variety, thereby distinguishing the museum from the standardized coffee shops. In spite of their special requirements, the couples were responsive to the other offerings (exhibitions, performances) of the museum, too. Some visitors may have discovered the museum initially and primarily as a dating venue, and then developed an interest in the objects exhibited there. They can, then, make use of it simultaneously as an opportunity for being together, and as the site of an exhibition.

In the case of the couples in this group of visitors, the appropriation of the institution, and the establishment of an attachment to it often precedes a meaningful reception of the exhibition and visits to events. This is a potentially fruitful observation as far as the attempt to vitalize museum life in India is concerned, since it suggests that enhancing the attractiveness of museums does not depend only on new exhibits, forms of presentation or types of exhibitions. Instead, attention must be focused in a special way on the visitors - on their social requirements, and on the possible contribution which the museum could make to their fulfilment.

Received: 19 October 2017

Finally Accepted: 26 March 2018

\section{Acknowledgement:}

The author thanks the Wilhelm von Pochhammer Memorial Fund for their support.

\section{Notes}

1 Dating in the context of this essay is understood: '... as the activities intended to establish and pursue a romantic relationship...' (Quah \& Kamugai, 2015: 111), i.e. those modes of behaviour and needs of couples in and in relation to museums will be discussed here which have a bearing upon their emotional-intimate relationship. For a classification of 'dating' in the typology of relationships as distinct from 'courtship' (wooing with the aim of marriage) and matrimony see Smith 1961 and Manderson, Liamputtony 2002 et al.

2 Indira Gandhi Rashtriya Manav Sangrahalaya

3 The figures are from the annual report of the museum to the Department of Culture, Government of MP from 2015. Unlike places like Agra, Jaipur or Udaipur, Bhopal is not located on the must-see-route for international tourists to India.

4 Section 294 of the Indian Penal Code (IPC). Section 294 of the IPC states:

Whoever, to the annoyance of others, (a) does any obscene act in any public place, or (b) sings, recites or utters any obscene songs, ballad or word, in or near any public place, shall be punished with imprisonment of either description for a term which may extend to three months, or with fine, or with both.

The pedantic and aggressive interpretation of this section by the police who invoke the law to seek out and harass couples in public parks or spaces has triggered a debate in the Indian media. 
5 Interview by author, in English, digital recording, 19 November 2015, Bhopal.

6 The study lasted six months (from February to July 1985) and covered 50 families.

7 A quantitative study with 500 visitors to the New Delhi Museum of Natural History was carried out by Chakrabarti over a period of four months in order to rate museum services (Chakrabarti 2007: 116-31).

8 In her study on intimacy, love and romance in cinema, Dwyer describes for instance a scene from the film 'Bobby' (direction: Raj Kapoor) in which a young unmarried couple dreams of being locked up in a room the key to which is lost so that no one from the family can gain access (Dwyer 2006: 296).

$9 \quad$ See also Phadke 2005, 2007.

10 The numbers in parentheses are the age stated. Interview by author, in English, digital recording, 19 November 2015, Bhopal.

11 Unless otherwise specified, the interviewees are Hindus.

12 The educational level of the interviewees in other user groups in the study varies significantly more.

13 Interview by author, in Hindi, digital recording, 22 March 2016, Bhopal.

14 Interview by author, in English, digital recording, 26 March 2016, Bhopal.

15 Nagpur is a city in the state of Maharashtra.

16 Interview by author, in English, digital recording, 27 March 2016, Bhopal.

17 Interview by author, in Hindi, digital recording, 19 November 2015, Bhopal.

18 Interview by author, in English, digital recording, 20 November 2015, Bhopal.

19 In this context see the section about spaces at the beginning of the essay.

20 These user interests are obviously temporary and biographically determined. Interviews with the same people in a different stage of life would probably produce different results.

21 It would take further studies about the disciplining effect of the museum as an institution in India on its visitors for these statements to become applicable to India in general.

22 See the section titled 'The spatial requirements for a good dating venue'

\section{References}

Appadurai, A., Breckenridge, C. (2015) 'Museums are Good to Think: Heritage on View in India', in Saloni Mathur and Kavita Singh (eds) No touching, no spitting, no praying. The Museum in South Asia, 173-184, London, New York, New Delhi: Routledge.

Banerjee, N.R. (1990) Museum and Cultural Heritage in India, Delhi: Agam Kala Prakashan.

Bennett, T. (1995) The Birth of the Museum. History, theory, politics, Oxford, New York: Routledge. 
Biswas, M. (2000) 'The Couple and Their Spaces: Harano Sur as Melodrama Now', in Ravi S. Vasudevan (ed) Making Meaning in Indian Cinema, 122-45, Oxford: Oxford University Press.

Brosius, C. (2011) Transcultural Turbulences. Towards a Multi-Sited Reading of Image Flows, Berlin, Heidelberg: Springer VS.

Chakrabarti, L. (2007) Managing Museums. A Study of the National Museum, New Delhi, Delhi: Sundeep Prakashan.

Doering, Z.D.(1999) 'Strangers, Guests or Clients? Visitor Experiences in Museums', Institutional Studies Smithsonian Institute, 1-27

Donner, H. (2016): 'Doing it our Way: Love and marriage in Kolkata middle-class families', Modern Asian Studies, 50 (4) 1147-89.

Duncan, C. (1995) Civilizing Rituals: Inside Public Art Museums, London, New York: Routledge.

Dwyer, R. (2000) All you want is money, all you need is love. Sex and Romance in Modern India, London, New York: Cassell.

(2006) 'Kiss or tell? Declaring love in Hindi films', in Francesca Orsini (ed) Love in South Asia: A Cultural History, 289-303, Cambridge: Cambridge University Press.

Elliott, M. (2006) 'Looking, Touching, and Interacting in the Indian Museum, Kolkata', Journal of Museum Ethnography, 18, 63-75.

Guha-Thakurta, T. (2004) Monuments, Objects, Histories. Institutions of Art in Colonial and Postcolonial India, Ranikhet: Permanent Black

(2015) 'The Museum in the Colony: Collecting, Conserving, Classifying', in Saloni Mathur and Kavita Singh (eds) No touching, no spitting, no praying. The Museum in South Asia, 45-83, London, New York, New Delhi: Routledge.

Hooper-Greenhill, E. (1989) 'The Museum in the Disciplinary Society' in Susan Pearce (ed) Museum Studies in Material Culture, 61-72, London: Leicester University Press.

Jain, J. (2012) 'Museum Effect', Lecture at the Workshop on the Comparative History of Museums in India and Europe, organised by the Indian European Advanced Research Network, Research Group on Museums and History, $14^{\text {th }}-15^{\text {th }}$ September 2012, Delhi, unpublished paper

Jeychandran, N. (2015) 'Government museum Chennai. Publics in a public space', in Saloni Mathur and Kavita Singh (eds) No touching, no spitting, no praying. The Museum in South Asia, 238-40, London, New York, New Delhi: Routledge.

Lukose, R. (2005) 'Consuming Globalization: Youth and Gender in Kerala, India', Journal of Social History, 38 (4) 915-35.

(2009) Liberalization's Children. Gender, Youth and Consumer Citzenship in Globalizing India, Durham, London: Duke University Press.

Manderson, L., Liamputtony, P. (2002) Introduction: Youth and Sexuality in Contemporary Asian Societies', in Lenore Manderson and Pranee Liamputtony (eds) Coming of Age in South and Southeast Asia: Youth, Courtship and Sexuality, 1-17, Richmond, Surrey: Curzon Press. 
Mathur, S. Singh, K. (eds) (2015) No touching, no spitting, no praying. The Museum in South Asia, London, New York, New Delhi: Routledge.

Mayring, P. (2015) Qualitative Inhaltsanalyse: Grundlagen und Techniken, Weinheim: Beltz.

Mazarella, W. (2001) 'Citizen have sex, consumer make love: Marketing KamaSutra Condoms in Bombay', in Brian Moeran (ed) Asian Media Productions, 168-97, Richmond, Surrey: Curzon Press.

Mazarella, W. (2014) 'Cultural Politics of Branding: Promoting 'KamaSutra' in India', in Nita Kumar, (ed) Consumer Culture, Modernity, and Identity, 204-38, New Delhi: Sage.

Mukherjee, S. (2015) 'A site museum without a site. The bodh gaya archeological museum', in Saloni Mathur and Kavita Singh (eds) No touching, no spitting, no praying. The Museum in South Asia, 45-83, London, New York, New Delhi: Routledge.

Mulgund, D. (2015) 'Imaginaries of the Art Museum: Banaras and Aundh in Colonial India', in Eva-Maria Troelenberg and Melania Savino (eds) Images of the Art Museum. Connecting Gaze and Discourse in the History of Museology, 215-37, Berlin: De Gruyter.

Naqvy, A., Venugopal, B., Falk, J. Dierking, L. (1991) 'The New Delhi National Museum of Natural History', Curator, 34 (1) 51-7.

Orsini, F. (ed) (2006) Love in South Asia: A Cultural History Cambridge: Cambridge University Press.

Phadke, S. (2005) "'You Can Be Lonely in a Crowd": The Production of Safety in Mumbai', Indian Journal of Gender Studies, 12 (1) 41-62.

(2007) 'Dangerous Liaisons. Women and Men: Risk and Reputation in Mumbai', Economic and Political Weekly, 42 (17) 1510-8.

Phadke, S., Khan, S., Ranade, S. (2011) Why Loiter? Women \& Risk on Mumbai Streets, Gurgaon: Penguin books.

Prakash, G. (1992) 'Science "Gone Native” in Colonial India', Representations, 40, 153-174

Quah, S. R. and Kamugai, F. (2015) 'Dating and Courtship', in Stella Quah (ed) Routledge Handbook of Families in Asia, 111-21, London, New York: Routledge, Taylor \& Francis Group.

Reichertz, J. (2017) 'Abduktion, Deduktion und Induktion in der qualitativen Forschung', in Uwe Flick, Ernst von Kardorff and Ines Steinke, (eds) Qualitative Forschung. Ein Handbuch, 276-286, Hamburg: Rowohlt.

Ross, I. (2015) 'Der Buddha und die Biennale. Wie sich Kulturmanagement in Indien neu erfindet - und was wir in Deutschland davon lernen können', Kulturpolitische Mitteilungen, 148 (1) 18-19.

(2017) 'Uncharted territory: Visitor books of Indian museums. The Madhya Pradesh Tribal Museum in Bhopal - a case study', Museum \& Society, 15 (1) 100-13.

Roychowdhury, M. (2015) Displaying India's Heritage. Archaeology and the Museum Movement in Colonial India, New Delhi: Orient Black Swan.

Singh, K. (2009) 'Material Fantasy. The Museum in Colonial India', in Gayatri Sinha (ed) Art and Visual Culture in India 1857-2007, 40-51, Mumbai: Marg Publications. 
Smith, H. (1961) 'Dating and courtship patterns, some explorations', The Journal of Educational Sociology, 35 (2) 49-58.

Srivastava, S. (2004) 'Introduction: Semen, History, Desire and Theory', in Sanjay Srivastava (ed) Sexual Sites, Seminal Attitudes. Sexualities, Masculinities and Culture in South Asia, 11-49, New Delhi: Sage, London: Thousand Oaks.

(2007) Passionate Modernity. Sexuality, Class, and Consumption in India, London, New York: Routledge,

Strauss, A. L. (1994) Grundlagen qualitativer Sozialforschung, München: Wilhelm Fink Verlag.

Trivedi, I. (2014) India in Love. Marriage and Sexuality in the 21st Century, New Delhi: Aleph.

*Ina Ross is lecturer for cultural management at the Jamia Millia Islamia University, Faculty of Fine Arts and the National School of Drama, New Delhi, India. Her Phd research is a visitor study on the Madhya Pradesh Tribal Museum in India. Her works include: (Forthcoming June 2018) 'Museum as a Space of Collective Nostalgia and Personal Memories - Madhya Pradesh Tribal Museum, Bhopal', Studies in Museology XLVIII, (2017) 'Uncharted territory: Visitor books of Indian museums. The Madhya Pradesh Tribal Museum in Bhopal - a case study', Museum \& Society, 15 (1) 100-13; (2017) 'Arts Management the Indian Way', International Journal of Arts Management, 19 (2) 59-69; (2017) 'The Mobile Theatre Movement in India: a Success Story in Assam', New Theatre Quarterly, 33 (1) 65-78; (2015)

Ina Ross,

K22 Hauz Khas Enclave

11001 New Delhi,

India

goegel@gmx.de 